\title{
Borrmann type IV gastric cancer should be classified as pT4b disease
}

Short title: Classifying Bor IV GC as pT4b disease

Jin-yu Huang, MD ${ }^{\text {a }}$, Zhen-ning Wang, MD, PhD ${ }^{\text {a }}$, Chun-yang Lu, MD ${ }^{\mathrm{a}}$, Zhi-feng Miao, MD,

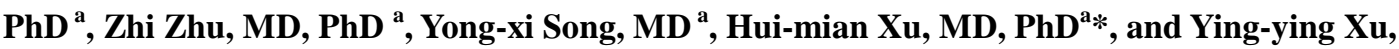

\section{$\mathrm{MD}, \mathrm{PhD}^{\mathrm{b}} *$}

${ }^{a}$ Department of Surgical Oncology, First Affiliated Hospital of China Medical University, Shenyang,

China

${ }^{\mathrm{b}}$ Department of Breast Surgery, First Affiliated Hospital of China Medical University, Shenyang, China

"Correspondence to: Hui-mian $\mathrm{Xu}$ and Ying-ying $\mathrm{Xu}$.

Dr H.-M. Xu, Department of Surgical Oncology, First Affiliated Hospital of China Medical University, Shenyang, Liaoning 110001, China. Tel: +86-13998303068; Fax: +86-24-22834060; E-mail: xuhuimian@126.com

Dr Y.-Y. Xu, Department of Breast Surgery, Department of Surgical Oncology, First Affiliated Hospital of China Medical University, Shenyang, Liaoning 110001, China. Tel: +86-13940521129; Fax: +86-24-22834060; E-mail: lovecmustar@163.com

The brief summary of each author's contribution: Hui-mian Xu, Ying-ying Xu and Jin-yu Huang were involved in study concept and design and writing the article; Jin-yu Huang, Chun-yang Lu, Zhi-feng Miao and Zhi Zhu were involved in analysis and interpretation of data; Yong-xi Song and Zhen-ning Wang were involved in data collection; Hui-mian Xu was involved in critical revision of the article, Ying-ying Xu was involved in obtaining funding. 


\begin{abstract}
Background: The impact of macroscopic pathological features of primary tumor that could be obtained preoperatively on $\mathrm{pT}$ classification has not been reported so far. The aim of this study was to investigate the feasibility of incorporation of Borrmann type IV gastric cancer into the pT classification.
\end{abstract}

Materials and methods: Clinicopathologic and prognostic data of 1622 patients with advanced gastric cancer who underwent radical surgery were retrospectively studied.

Results: Of 1622 patients, $135(8.32 \%)$ patients were classified as having Borrmann type IV gastric cancer. We first confirmed that Borrmann type IV gastric cancer was one of the independent prognostic factors for patients with advanced gastric cancer who underwent radical surgery. Interestingly, we found that overall survival of patients with Borrmann type IV gastric cancer could be clearly distinguished by pN classification and pTNM stage, but not by pT classification. Importantly, further analysis demonstrated that the prognosis of Borrmann type IV gastric cancers was homogeneous with that of pT4b cancers, but poorer than pT2, pT3, pT4a cancers. Therefore, we proposed a novel pT classification in which pT4b disease was defined as cancers that were Borrmann type IV or those that had invaded adjacent structures. Two-step multivariate analysis demonstrated that the novel pT classification was more suitable for prognostic assessment than the original classification.

Conclusions: Classifying Borrmann type IV gastric cancer as pT4b disease improves pT classification prediction of prognosis in patients with advanced gastric cancer after radical surgery.

Key words: gastric cancer, prognosis, Borrmann type, macroscopic types, pT, TNM. 


\section{Introduction}

Gastric cancer is the fourth most common malignancy worldwide, and about one million new cases of gastric cancer have been estimated to occur each year.[1,2] Although developments in diagnostic modalities have increased the diagnosis of early gastric cancer, most patients present with advanced diseases when they are diagnosed with gastric cancer. At present, penetration depth of the primary tumor ( $\mathrm{pT}$ classification) and the number of metastatic lymph nodes ( $\mathrm{pN}$ classification) are considered to be the most important prognostic factors in patients with advanced gastric cancer after radical surgery.[3-6] However, the pT classification and the pN classification can be only obtained accurately postoperatively. Recently, several papers reported that addition of macroscopic pathological features of primary tumor that could be obtained easily during operation, such as macroscopic serosal classification and width of serosal invasion, might improve $\mathrm{pT}$ classification prediction of prognosis in patients with advanced gastric cancer after radical surgery.[7,8] Unfortunately, the impact of the features that could be obtained preoperatively on $\mathrm{pT}$ classification has not been reported so far.

The Borrmann classification system is now widely used to classify advanced gastric cancer according to the macroscopic appearance of primary tumor. Borrmann type IV gastric cancer is characterized by a thickened and indurated gastric wall without a clear margin of tumor, which can be easily diagnosed by imaging examination or endoscopy preoperatively.[9] Borrmann type IV gastric cancer, which shows a more malignant biological behavior compared to other types of gastric cancer, has been demonstrated to be an independent factor predicting poor survival.[10-13] Nevertheless, the impact of Borrmann type IV gastric cancer on the pT classification has not been assessed. Therefore, in the present study, we retrospectively analyzed the clinicopathologic and prognostic data of 1622 patients with advanced gastric cancer after radical surgery in our center, to investigate the feasibility of 
incorporation of Borrmann type IV gastric cancer into the pT classification.

\section{Methods}

All patients with gastric cancer who underwent surgery at the Department of Surgical Oncology,

First Affiliated Hospital of China Medical University, from January 1980 to December 2005 were entered into a prospectively maintained database. In all, 1756 patients without distant metastasis underwent radical (R0) surgery for histologically proven advanced gastric carcinoma. A radical surgery was defined as en bloc resection of primary cancer and completed lymphadenectomy without microscopic or macroscopic residual disease according to the TNM staging system.[14] The completed lymphadenectomy referred to D2 or D3 lymphadenectomy according to Japanese gastric cancer treatment guidelines 2010 (ver. 3).[15] Among them, we excluded patients: (1) with a prior gastric surgery (23 patients), (2) without pathologic data of the TNM staging system or Borrmann types (49 patients), (3) who died in the postoperative period (the first 30 days after surgery, 20 patients), and (4) who were lost during the time of follow-up (42 patients). After these exclusions, a total of 1622 patients were enrolled into this study. All patients did not receive neoadjuvant chemotherapy.

Meanwhile, 261 gastric cancer patients with distant metastasis (M1) who underwent surgeries during the same study period were included as a reference group for prognostic comparisons with Borrmann IV gastric cancer patients who underwent radical surgery. All patients in the reference group with distant metastasis underwent palliative operation, and did not receive neoadjuvant therapy.

Follow-up of the entire study population was conducted until death or the cutoff date (March 31, 2009) by means of outpatient clinic consultation and/or communication with patients through telephone or letter. Median and mean follow-up periods were 38 and 59.81 months (range: 1-319 months), respectively. 
Of the 1622 patients, the following clinicopathologic features were obtained: age, gender, location of the primary tumor, tumor size, pT classification, $\mathrm{pN}$ classification, pTNM stage, histologic type, lymphovascular invasion, and Borrmann type. The pT classification, $\mathrm{pN}$ classification, and pTNM stage were classified according to the seventh International Union Against Cancer (UICC)/American Joint Committee on Cancer (AJCC) TNM staging system.[3] Borrmann type classification was classified according to the Japanese Classification of Gastric Carcinoma.[9] Borrmann type IV gastric cancer was diagnosed when the following characteristics were observed: thickened and indurated gastric wall; no obvious protruded lump or deep ulceration; hypertrophic gastric folds; narrow gastral cavity; even a leather-bottle-like stomach. (Fig. S1)

All statistical analyses were performed with the SPSS 19.0 statistical package (SPSS Inc., Chicago, IL, USA). The categorical variables were compared using a 2-tailed chi-square test. The continuous data was presented as a mean \pm standard deviation (SD), and 2-tailed t test was used for the statistical comparisons. All the clinicopathologic features that were significantly associated with Borrmann type IV gastric cancer were included in the logistic regression analysis (stepwise forwards method) to identify the independent predictors of the presence of Borrmann type IV gastric cancer. Overall survival rates were determined using the Kaplan-Meier estimator, and the log-rank test was used to identify differences between the survival curves of different patient groups. Cox's proportional hazard model was used as multivariate analysis to identify independent factors predicting patients' prognosis.

For all analyses, $P$ values were 2 -tailed, and only $P$ values $<0.05$ were considered significant.

\section{Results}

Of the 1622 patients enrolled in the present study, there were 1195 men (73.7\%) and 427 women (26.3\%; ratio, 2.8:1), with a mean age of $58.09 \pm 10.8$ years (median, 59 years; range, 17-90 years). 
Among these patients, 44 (2.71\%) were Borrmann type I, 310 (19.11\%) were Borrmann type II, 1107 (68.25\%) were Borrmann type III, $135(8.32 \%)$ were Borrmann type IV, and $26(1.61 \%)$ were Borrmann type V. Table 1 summarizes the clinicopathologic features of the 135 patients with Borrmann type IV gastric cancer and the 1487 patients with the other types of gastric cancer. There were significant differences in age, gender, location of the primary tumor, tumor size, $\mathrm{pT}$ classification, pN classification, pTNM stage, lymphovascular invasion, and histologic type. Logistic regression analysis revealed that gender, location of the primary tumor, tumor size, and histologic type were the independent predictors of the presence of Borrmann type IV gastric cancer (Table 2).

Concerning prognosis, the 5-year survival rate (5-YSR) of patients with Borrmann type IV gastric cancer was significantly poorer than that of the other types of gastric cancer (Fig. 1; 5-YSR: 19.7\% vs. 45.3\%; $P=0.000$ ), but significantly better than that of those with distant metastasis (Fig. 1; 5-YSR: $19.7 \%$ vs. $7.5 \% ; P=0.000)$. When the overall survival rates were compared as stratified by $\mathrm{pT}$ classification, pN classification, and pTNM stage respectively, a significant difference could be observed between patients with Borrmann type IV gastric cancer and those with other types of gastric cancer in pT2-pT4a classification, pN0-pN3a classification, and stage IIa and IIIa-IIIc disease, but not in pT4b classification, pN3b classification, and stage Ib and IIb disease (Table 3).

Subsequently, we compared the overall survival according to $\mathrm{pT}$ classification, $\mathrm{pN}$ classification, and pTNM stage in the 135 patients with Borrmann IV gastric cancer. For pN classification, there were significant prognostic differences in survival among patients with different classifications (Table 3; $P=0.000$ ). For pTNM stage, there were also significant differences in survival among patients with different stages (Table $3 ; P=0.000$ ). However, for $\mathrm{pT}$ classification, significant differences in survival could not be observed among patients with different classifications (Table 3; $P=0.242$ ). We also 
compared the overall survival according to $\mathrm{pT}$ classification, $\mathrm{pN}$ classification, and pTNM stage in the 1475 patients with other types of gastric cancer. We found that there were significant prognostic differences in survival among patients with different $\mathrm{pT}$ classifications, different $\mathrm{pN}$ classifications, and different pTNM stages (Table 3, $P=0.000$ for all three comparisons).

Since there was no difference in overall survival among pT2, pT3, pT4a, and pT4b patients with Borrmann type IV gastric cancer, we compared the prognosis of all 135 patients with Borrmann type IV gastric cancer with that of pT2, pT3, pT4a, and pT4b patients with other types of gastric cancer, respectively. Interestingly, as Fig. 2 shows, the prognosis of patients with Borrmann type IV gastric cancer was similar to that of pT4b patients with other types of gastric cancer (5-YSR: 19.7\% vs. 20.6\%; $P=0.898$ ) but significantly poorer than that of pT2, pT3 and pT4a patients with other types of gastric cancer $(P=0.000$ for all the three comparisons). We also compared the overall survival of all pT4b patients with that of pT2, pT3, pT4a patients with Borrmann type IV gastric cancer, respectively. We found that the prognosis of pT4b patients was similar to that of pT2, pT3, pT4a patients with Borrmann type IV gastric cancer, respectively (Fig. $3 ; P=0.207, P=0.772, P=0.891$, respectively).

Based on these results, we proposed a novel pT classification, in which pT4b classification disease was defined as cancers that were Borrmann type IV or invaded adjacent structures. The survival curves according to each of the T classifications were well separated both in the UICC/AJCC pT classification and in the novel pT classification (Fig. $4 ; P=0.000$ for both). To explore which pT classification was more suitable for prognostic assessment, we performed 2-step multivariate analysis for survival of patients with radical surgery. Univariate analysis of prognostic factors suggested that age, location of the primary tumor, tumor size, UICC/AJCC pT classification, $\mathrm{pN}$ classification, histologic type, lymphovascular invasion, Borrmann type, and the novel pT classification were significantly correlated 
with patient prognosis (Table 4). In step 1 multivariate analysis, all the significant prognostic factors in the univariate analysis were considered except for the novel pT classification. We found that age, location of the primary tumor, $\mathrm{pT}$ classification, $\mathrm{pN}$ classification, lymphovascular invasion, and Borrmann type were independent factors predicting patients' prognosis (Table 5). When the novel pT classification was also considered in step 2 multivariate analysis, it replaced the UICC/AJCC pT classification as one of the most important prognostic factors (Table 5).

\section{Discussion}

Since the Borrmann classification system was developed in 1926, it has been generally accepted and widely adopted. It is widely reported that Borrmann type IV gastric cancer is an independent factor predicting poor survival for patients with advanced gastric cancer.[10-13] Nevertheless, the feasibility of incorporation of Borrmann type IV gastric cancer into the pT classification has not been investigated. The findings of the present study suggest that Borrmann type IV gastric cancer should be classified as pT4b disease.

In this study, we found that overall survival of patients with Borrmann type IV gastric cancer could be clearly distinguished by pN classification and pTNM stage, but not by pT classification, suggesting that pT classification of the UICC/ AJCC TNM staging system needs improvement. Importantly, our data demonstrated that the prognosis of Borrmann type IV gastric cancers was homogeneous with that of $\mathrm{pT} 4 \mathrm{~b}$ cancers. Therefore, we proposed a novel $\mathrm{pT}$ classification, in which in which pT4b classification disease was defined as cancers that were Borrmann type IV or invaded adjacent structures. By using 2-step multivariate analysis, we confirmed that the novel pT classification was superior to the UICC/AJCC pT classification in prediction of prognosis in patients with advanced gastric cancer after radical surgery. 
The UICC/AJCC TNM staging system is used to determine treatment options for advanced gastric cancer patients worldwide.[16,17] However, the pT classification and the pN classification can be only obtained accurately postoperatively. On the contrary, Borrmann type IV gastric cancer can be easily diagnosed by imaging examination preoperatively.[18] Considering the prognostic value of Borrmann type IV gastric cancer and its impact on the UICC/AJCC pT classification, we speculate that Borrmann type IV gastric cancer may be an indicator of receiving neoadjuvant chemotherapy and intraoperative intraperitoneal chemotherapy. We plan to test this speculation in our future researches.

In addition to being utilized for deciding treatment options, the UICC/AJCC TNM staging system is usually utilized for patient stratification during experimental design to assess treatment effect.[19,20] However, few studies have considered the importance of the equal distribution of patients with Borrmann type IV gastric cancer between the experimental group and control group when they design a study. For example, Nakajima et al.[21] conducted a randomized controlled trial to compare the survival of patients with pT2-3 classification gastric cancer treated by radical surgery alone or radical surgery followed by uracil-tegafur. They reported a significant survival benefit of postoperative adjuvant chemotherapy, which increased the 5-year survival rate by $11 \%$. However, the study did not state whether the distribution of patients with Borrmann type IV between the experimental group and control group was equal. If it was not, we think the results reported by Nakajima et al. should be further analyzed considering the significant differences in prognosis that were observed between patients with Borrmann type IV gastric cancer and those with other types of gastric cancer in pT2-3 classification in the present study. Furthermore, under this condition, the novel pT classification proposed by us may be more suitable for patient stratification to assess the treatment effect.

In this study, we found that patients with Borrmann type IV gastric cancer were characterized by 
young age, female predominance, large tumor sizes, tumor occupying the entire stomach, undifferentiated histologic type, lymphovascular invasion, advanced pT classification, advanced pN classification, and advanced pTNM stage in patients with radical surgery. Logistic regression analysis revealed that gender, location of the primary tumor, tumor size, and histologic type were the independent predictors of the presence of Borrmann type IV gastric cancer. These findings are in agreement with previous reports[10-13] and shows that Borrmann type IV gastric cancer has more aggressive biologic behaviors compared to other types of gastric cancer, which should be considered as a special subset of advanced gastric cancer. In addition, we noticed that $8.32 \%$ of advanced gastric cancer was Borrmann type IV in the present study, whereas those reported by previous studies ranged from $9 \%$ to $18 \% .[11,13,22,23]$ The reason for the relatively lower proportion of Borrmann type IV gastric cancer reported by us might be that only patients who underwent radical surgery were included in the present study.

A recent study by Yang et al., in which patients who did not undergo radical surgery were included, demonstrated that the survival of patients with Borrmann type IV gastric cancer was similar to those with distant metastasis (M1), and they suggested that Borrmann type IV gastric cancer should be classified as stage IV disease.[10] On the contrary, in the present study, we found that the prognosis of patients with Borrmann type IV gastric cancer who underwent radical surgery was significantly better than that of patients with distant metastasis. Therefore, according to our results, patients with Borrmann type IV gastric cancer should not be classified as stage IV disease when they underwent radical surgery.

There are some limitations in the present study. First, although we compared the prognosis between patients with Borrmann type IV gastric cancer and patients with other types of gastric cancer 
stratified by $\mathrm{pT}$ classification, $\mathrm{pN}$ classification, and $\mathrm{pTNM}$ stage to investigate the prognostic value of Borrmann type IV gastric cancer in as much detail as possible, we could not compare overall survival between these two groups stratified by "any T + any N" classification because of the limited number of patients with Borrmann type IV gastric cancer in the present study. Second, our conclusion resulted from a Chinese monoinstitutional study in 1622 patients. Therefore, larger studies with multicentric data such as Surveillance Epidemiology and End Results (SEER) database should be performed to confirm our results.

\section{Conclusions}

In summary, we investigated the feasibility of incorporation of Borrmann type IV gastric cancer into the $\mathrm{pT}$ classification, and found that Borrmann type IV gastric cancer should be classified as pT4b disease. However, our conclusion just resulted from a Chinese monoinstitutional study in 1622 patients, and larger studies with multicentric data such as Surveillance Epidemiology and End Results (SEER) database should be performed to confirm our results.

Acknowledgments: This work was supported by National Science Foundation of China (No.81372550) and Key Laboratory Programme of Liaoning Province (LZ2015080).

Disclosure: The authors report no proprietary or commercial interest in any product mentioned or concept discussed in this article. 


\section{References}

1. Jemal A, Bray F, Center MM, Ferlay J, Ward E, Forman D. Global cancer statistics. CA Cancer J Clin. 2011;61:69-90.

2. Ferlay J, Shin HR, Bray F, Forman D, Mathers C, Parkin DM. Estimates of worldwide burden of cancer in 2008: GLOBOCAN 2008. Int J Cancer. 2010;127:2893-2917.

3. Sobin LH, Gospodarowicz MK, Witterkind CH, eds. International Union Against Cancer (UICC) TNM Classification of Malignant Tumors. 7th ed. Oxford: Wiley-Blackwell; 2009.

4. Marrelli D, Morgagni P, de Manzoni G, Coniglio A, Marchet A, Saragoni L, Tiberio G, Roviello F; Italian Research Group for Gastric Cancer (IRGGC). Prognostic value of the 7th AJCC/UICC TNM classification of noncardia gastric cancer: analysis of a large series from specialized Western centers. Ann Surg. 2012;255:486-491.

5. Hayashi T, Yoshikawa T, Bonam K, Sue-Ling HM, Taguri M, Morita S, Tsuburaya A, Hayden JD, Grabsch HI. The superiority of the seventh edition of the TNM classification depends on the overall survival of the patient cohort: comparative analysis of the sixth and seventh TNM editions in patients with gastric cancer from Japan and the United Kingdom. Cancer. 2013;119:1330-1337.

6. Huang JY, Xu YY, Li M, Sun Z, Zhu Z, Song YX, Miao ZF, Wu JH, Xu HM. The prognostic impact of occult lymph node metastasis in node-negative gastric cancer: a systematic review and meta-analysis. Ann Surg Oncol. 2013;20:3927-3934.

7. Wang HH, Huang JY, Wang ZN, Sun Z, Li K, Xu HM. Macroscopic serosal classification as a prognostic index in radically resected stage pT3-pT4b gastric cancer. Ann Surg Oncol. 2016;23:149-155.

8. Kang Y, Wang F, Zu H, Yang Z, Xue Y. A new subclassification of pT4 gastric cancers according to 
the width of serosal invasion. PLoS One. 2013;8:e68042.

9. Japanese Gastric Cancer Association. Japanese classification of gastric carcinoma: 3rd English edition. Gastric Cancer. 2011;14:101-112.

10. Yang B, Wu G, Wang X, Zhang X. Discussion of modifying stage IV gastric cancer based on Borrmann classification. Tumour Biol. 2013;34:1485-1491.

11. An JY, Kang TH, Choi MG, Noh JH, Sohn TS, Kim S. Borrmann type IV: an independent prognostic factor for survival in gastric cancer. J Gastrointest Surg. 2008;12:1364-1369.

12. Li C, Oh SJ, Kim S, Hyung WJ, Yan M, Zhu ZG, Noh SH. Macroscopic Borrmann type as a simple prognostic indicator in patients with advanced gastric cancer. Oncology. 2009;77:197-204.

13. Yook JH, Oh ST, Kim BS. Clinicopathological analysis of Borrmann type IV gastric cancer. Cancer Res Treat. 2005;37:87-91.

14. Sobin LH, Wittekind CH. International Union Against Cancer. TNM classification of malignant tumors. 6th ed. New York: John Wiley-Liss; 2002.

15. Japanese Gastric Cancer Association. Japanese gastric cancer treatment guidelines 2010 (ver. 3). Gastric Cancer. 2011;14:113-123.

16. Park SH, Sohn TS, Lee J, Lim do H, Hong ME, Kim KM, Sohn I, Jung SH, Choi MG, Lee JH, Bae JM, Kim S, Kim ST, Park JO, Park YS, Lim HY, Kang WK. Phase III Trial to Compare Adjuvant Chemotherapy With Capecitabine and Cisplatin Versus Concurrent Chemoradiotherapy in Gastric Cancer: Final Report of the Adjuvant Chemoradiotherapy in Stomach Tumors Trial, Including Survival and Subset Analyses. J Clin Oncol. 2015;33:3130-3136.

17. Noh SH, Park SR, Yang HK, Chung HC, Chung IJ, Kim SW, Kim HH, Choi JH, Kim HK, Yu W, Lee JI, Shin DB, Ji J, Chen JS, Lim Y, Ha S, Bang YJ; CLASSIC trial investigators. Adjuvant 
capecitabine plus oxaliplatin for gastric cancer after D2 gastrectomy (CLASSIC): 5-year follow-up of an open-label, randomised phase 3 trial. Lancet Oncol. 2014;15:1389-1396.

18. Zhang XP, Tang L, Sun YS, Li ZY, Ji JF, Li XT, Liu YQ, Wu Q. Sandwich sign of Borrmann type 4 gastric cancer on diffusion-weighted magnetic resonance imaging. Eur J Radiol. 2012;81:2481-2486.

19. Sakuramoto S, Sasako M, Yamaguchi T, Kinoshita T, Fujii M, Nashimoto A, Furukawa H, Nakajima T, Ohashi Y, Imamura H, Higashino M, Yamamura Y, Kurita A, Arai K; ACTS-GC Group. Adjuvant chemotherapy for gastric cancer with $\mathrm{S}-1$, an oral fluoropyrimidine. $\mathrm{N}$ Engl J Med. 2007;357:1810-1820.

20. Jeung HC, Moon YW, Rha SY, Yoo NC, Roh JK, Noh SH, Min JS, Kim BS, Chung HC. Phase III trial of adjuvant 5-fluorouracil and adriamycin versus 5-fluorouracil, adriamycin, and polyadenylic-polyuridylic acid (poly A:U) for locally advanced gastric cancer after curative surgery: final results of 15-year follow-up. Ann Oncol. 2008;19:520-526.

21. Nakajima T, Kinoshita T, Nashimoto A, Sairenji M, Yamaguchi T, Sakamoto J, Fujiya T, Inada T, Sasako M, Ohashi Y; National Surgical Adjuvant Study of Gastric Cancer Group. Randomized controlled trial of adjuvant uracil-tegafur versus surgery alone for serosa-negative, locally advanced gastric cancer. Br J Surg. 2007;94:1468-1476.

22. Kim DY, Kim HR, Kim YJ, Kim S. Clinicopathological features of patients with Borrmann type IV gastric carcinoma. ANZ J Surg. 2002;72:739-742.

23. Otsuji E, Yamaguchi T, Sawai K, Sakakura C, Okamoto K, Takahashi T. Regional lymph node metastasis as a predictor of peritoneal carcinomatosis in patients with Borrmann type IV gastric carcinoma. Am J Gastroenterol. 1999;94:434-437. 


\section{Figure legends}

Fig. 1. Comparison of survival curves between patients with Borrmann type IV gastric cancer and with other types of gastric cancer, and those with distant metastasis.

Fig. 2. Comparison of survival curves between patients with Borrmann type IV gastric cancer and pT2 patients with other types of gastric cancer (a), between patients with Borrmann type IV gastric cancer and pT3 patients with other types of gastric cancer (b), between patients with Borrmann type IV gastric cancer and pT4a patients with other types of gastric cancer (c), and between patients with Borrmann type IV gastric cancer and pT4b patients with other types of gastric cancer (d).

Fig. 3. Comparison of survival curves between pT4b patients and pT2 patients with Borrmann type IV gastric cancer (a), between pT4b patients and pT3 patients with Borrmann type IV gastric cancer (b), between pT4b patients and pT4a patients with Borrmann type IV gastric cancer (c).

Fig. 4. (a), Survival curves according to the UICC/AJCC pT classification. (b), Survival curves according to the novel pT classification. 
Table 1. Comparison of clinicopathologic features between Borrmann type IV gastric cancer and other type gastric cancer.

\begin{tabular}{|c|c|c|c|}
\hline Factors & Borrmann type IV (\%) & Other Borrmann types $(\%)$ & $P$ value \\
\hline Age $(\text { year })^{a}$ & $56.13 \pm 11.79$ & $58.26 \pm 10.72$ & 0.029 \\
\hline Gender & & & 0.000 \\
\hline Male & $81(60)$ & $1114(74.9)$ & \\
\hline Female & $54(40)$ & $373(25.1)$ & \\
\hline Location & & & 0.000 \\
\hline Upper $1 / 3$ & $10(7.4)$ & $230(15.5)$ & \\
\hline Middle 1/3 & $17(12.6)$ & $223(15)$ & \\
\hline Lower $1 / 3$ & $65(48.1)$ & $982(66.2)$ & \\
\hline Entire & $43(31.9)$ & $49(3.3)$ & \\
\hline Tumor size $(\mathrm{cm})^{a}$ & $7.57 \pm 3.45$ & $5.29 \pm 2.29$ & 0.000 \\
\hline pT classification & & & 0.000 \\
\hline $\mathrm{T} 2$ & $11(8.1)$ & $323(21.7)$ & \\
\hline $\mathrm{T} 3$ & $64(47.4)$ & $735(49.4)$ & \\
\hline $\mathrm{T} 4 \mathrm{a}$ & $46(34.1)$ & $338(22.7)$ & \\
\hline $\mathrm{T} 4 \mathrm{~b}$ & $14(10.4)$ & $91(6.1)$ & \\
\hline $\mathrm{pN}$ classification & & & 0.000 \\
\hline N0 & $27(20)$ & $469(31.5)$ & \\
\hline N1 & $17(12.6)$ & $340(22.9)$ & \\
\hline $\mathrm{N} 2$ & $38(28.1)$ & $327(22)$ & \\
\hline $\mathrm{N} 3 \mathrm{a}$ & $32(23.7)$ & $262(17.6)$ & \\
\hline $\mathrm{N} 3 \mathrm{~b}$ & $21(15.6)$ & $89(6)$ & \\
\hline pTNM stage & & & 0.000 \\
\hline Ia & $4(3)$ & $148(10)$ & \\
\hline IIa & $14(10.4)$ & $307(20.6)$ & \\
\hline $\mathrm{IIb}$ & $20(14.8)$ & 288(19.4) & \\
\hline IIIa & $28(20.7)$ & $278(18.7)$ & \\
\hline IIIb & $41(30.4)$ & $327(22)$ & \\
\hline IIIc & $28(20.7)$ & $139(9.3)$ & \\
\hline Histologic type & & & 0.000 \\
\hline Differentiated & $17(12.6)$ & $562(38.3)$ & \\
\hline Undifferentiated & $118(87.4)$ & $906(61.7)$ & \\
\hline Lymphovascular invasion & & & 0.003 \\
\hline No & $82(63.6)$ & 1053(75.4) & \\
\hline Yes & $47(36.4)$ & $343(24.6)$ & \\
\hline
\end{tabular}

${ }^{\mathrm{a}}$ 2-tailed t test 
Table 2. Logistic regression analysis of clinicopathologic features correlated with Borrmann type IV gastric cancer.

\begin{tabular}{llll}
\hline Factors & RR & $95 \% \mathrm{CI}$ & $P$ value \\
\hline $\begin{array}{l}\text { Gender } \\
\text { Male }\end{array}$ & & 0.015 \\
Female & 1.716 & $1.110-2.652$ & \\
Location & & & 0.000 \\
Entire & & & \\
Upper 1/3 & 0.122 & $0.052-0.285$ & \\
Middle 1/3 & 0.207 & $0.101-0.427$ & \\
Lower 1/3 & 0.164 & $0.091-0.296$ & 0.000 \\
Tumor size & 1.256 & $1.164-1.354$ & 0.000 \\
Histologic type & & & \\
Differentiated & & & \\
Undifferentiated & 3.719 & $2.090-6.618$ & \\
\hline Abbreviations: RR & & & \\
\hline
\end{tabular}

Abbreviations: RR, relative risk; CI, confidence interval. 
Table 3. Comparison of overall survival according to Borrmann type stratified by the TNM staging system and according to the TNM staging system stratified by Borrmann type respectively.

\begin{tabular}{|c|c|c|c|c|c|c|c|}
\hline & \multicolumn{3}{|c|}{ Borrmann type IV } & \multicolumn{3}{|c|}{ Other Borrmann types } & \multirow[b]{2}{*}{$P$ value $^{\mathrm{c}}$} \\
\hline & $\mathrm{N}$ & 5-YSR(\%) & $P$ value $^{\mathrm{a}}$ & $\mathrm{N}$ & 5-YSR(\%) & $P$ value $^{\mathrm{b}}$ & \\
\hline pT classification & & & 0.242 & & & 0.000 & \\
\hline $\mathrm{T} 2$ & 11 & 27.3 & & 323 & 66 & & 0.023 \\
\hline $\mathrm{T} 3$ & 64 & 22.9 & & 735 & 45.7 & & 0.000 \\
\hline $\mathrm{T} 4 \mathrm{a}$ & 46 & 16.9 & & 338 & 32.2 & & 0.008 \\
\hline $\mathrm{T} 4 \mathrm{~b}$ & 14 & 14.3 & & 91 & 20.6 & & 0.106 \\
\hline pN classification & & & 0.000 & & & 0.000 & \\
\hline No & 27 & 38.9 & & 469 & 68 & & 0.012 \\
\hline $\mathrm{N} 1$ & 17 & 29.4 & & 340 & 50 & & 0.037 \\
\hline $\mathrm{N} 2$ & 38 & 24.6 & & 327 & 34.8 & & 0.028 \\
\hline N3a & 32 & 0 & & 262 & 24 & & 0.000 \\
\hline N3b & 21 & 10.3 & & 89 & 8.9 & & 0.262 \\
\hline pTNM stage & & & 0.000 & & & 0.000 & \\
\hline $\mathrm{Ib}$ & 4 & 50 & & 148 & 75.4 & & 0.539 \\
\hline IIa & 14 & 28.6 & & 307 & 73.2 & & 0.000 \\
\hline $\mathrm{IIb}$ & 20 & 45 & & 288 & 48.3 & & 0.859 \\
\hline IIIa & 28 & 20.4 & & 278 & 37.6 & & 0.018 \\
\hline $\mathrm{IIIb}$ & 41 & 12.6 & & 327 & 21.7 & & 0.004 \\
\hline IIIc & 28 & 3.6 & & 139 & 17.7 & & 0.006 \\
\hline
\end{tabular}

Abbreviations: 5-YSR, 5 year survival rate.

${ }^{a}$ Comparison of overall survival according to pT classification, $\mathrm{pN}$ classification, and pTNM stage in 135 patients with Borrmann type IV gastric cancer respectively.

${ }^{\mathrm{b}}$ Comparison of overall survival according to pT classification, pN classification, and pTNM stage in 1487 patients with other type gastric cancer respectively.

${ }^{\mathrm{c}}$ Comparison of overall survival according to Borrmann type stratified by pT classification, pN classification, and pTNM stage in 1622 patients with advanced gastric cancer respectively. 
Table 4. Univariate analysis of prognostic factors for patients with advanced gastric cancer who underwent radical surgery.

\begin{tabular}{|c|c|c|c|}
\hline Factors & $\mathrm{n}$ & 5-YSR (\%) & $P$ value $^{\mathrm{a}}$ \\
\hline Age & & & 0.001 \\
\hline$\leq 60$ years & 903 & 45.1 & \\
\hline$>60$ years & 719 & 40.8 & \\
\hline Gender & & & 0.920 \\
\hline Male & 1195 & 43.2 & \\
\hline Female & 427 & 43.3 & \\
\hline Location & & & 0.000 \\
\hline Entire & 86 & 16.8 & \\
\hline Upper $1 / 3$ & 240 & 33.4 & \\
\hline Middle 1/3 & 241 & 48.5 & \\
\hline Lower $1 / 3$ & 1052 & 46.4 & \\
\hline Tumor size & & & 0.000 \\
\hline$\leq 4 \mathrm{~cm}$ & 584 & 51.6 & \\
\hline$>4 \mathrm{~cm}$ & 989 & 38.4 & \\
\hline UICC/AJCC pT classification & & & 0.000 \\
\hline $\mathrm{T} 2$ & 334 & 64.6 & \\
\hline $\mathrm{T} 3$ & 799 & 43.9 & \\
\hline $\mathrm{T} 4 \mathrm{a}$ & 384 & 30.4 & \\
\hline $\mathrm{T} 4 \mathrm{~b}$ & 105 & 19.8 & \\
\hline pN classification & & & 0.000 \\
\hline No & 496 & 66.4 & \\
\hline N1 & 357 & 49 & \\
\hline $\mathrm{N} 2$ & 365 & 33.8 & \\
\hline $\mathrm{N} 3 \mathrm{a}$ & 294 & 21.3 & \\
\hline $\mathrm{N} 3 \mathrm{~b}$ & 110 & 9 & \\
\hline Histologic type & & & 0.008 \\
\hline Differentiated & 579 & 47.4 & \\
\hline Undifferentiated & 1024 & 40.4 & \\
\hline Lymphovascular invasion & & & 0.000 \\
\hline No & 1135 & 48.7 & \\
\hline Yes & 390 & 28 & \\
\hline Borrmann type & & & 0.000 \\
\hline Other types & 1487 & 45.3 & \\
\hline Type IV & 135 & 19.7 & \\
\hline Novel pT classification & & & 0.000 \\
\hline $\mathrm{T} 2$ & 323 & 66.0 & \\
\hline $\mathrm{T} 3$ & 735 & 45.7 & \\
\hline $\mathrm{T} 4 \mathrm{a}$ & 338 & 32.2 & \\
\hline $\mathrm{T} 4 \mathrm{~b}$ & 226 & 20.3 & \\
\hline
\end{tabular}

Abbreviations: 5-YSR, 5 year survival rate; UICC, International Union Against Cancer; AJCC, American Joint Committee on Cancer. 
${ }^{\text {a }} P$ value was determined by log-rank test 
Table 5. Two-step multivariate analysis of prognostic factors for patients with advanced gastric cancers who underwent radical surgery.

\begin{tabular}{|c|c|c|c|c|c|c|}
\hline \multirow[b]{2}{*}{ Factors } & \multicolumn{3}{|c|}{ Step $1^{\mathrm{a}}$} & \multicolumn{3}{|c|}{ Step $2^{b}$} \\
\hline & HR & $95 \% \mathrm{CI}$ & $P$ value & HR & $95 \% \mathrm{CI}$ & $P$ value \\
\hline Age & & & 0.000 & & & 0.000 \\
\hline \multicolumn{7}{|l|}{$\leq 60$ years } \\
\hline$>60$ years & 1.324 & $1.167-1.503$ & & 1.325 & $1.167-1.503$ & \\
\hline Location & & & 0.000 & & & 0.000 \\
\hline \multicolumn{7}{|l|}{ Entire } \\
\hline Upper $1 / 3$ & 0.991 & $0.728-1.349$ & & 0.945 & $0.706-1.264$ & \\
\hline Middle 1/3 & 0.623 & $0.456-0.849$ & & 0.597 & $0.445-0.801$ & \\
\hline Lower $1 / 3$ & 0.630 & $0.476-0.834$ & & 0.602 & $0.464-0.781$ & \\
\hline UICC/AJCC pT classification & & & 0.000 & & & \\
\hline \multicolumn{7}{|l|}{$\mathrm{T} 2$} \\
\hline $\mathrm{T} 3$ & 1.375 & $1.141-1.657$ & & & & \\
\hline $\mathrm{T} 4 \mathrm{a}$ & 1.590 & $1.298-1.948$ & & & & \\
\hline $\mathrm{T} 4 \mathrm{~b}$ & 2.237 & $1.685-2.970$ & & & & \\
\hline $\mathrm{pN}$ classification & & & 0.000 & & & 0.000 \\
\hline \multicolumn{7}{|l|}{ N0 } \\
\hline N1 & 1.465 & $1.214-1,767$ & & 1.469 & $1.218-1.772$ & \\
\hline $\mathrm{N} 2$ & 1.958 & $1.628-2.356$ & & 1.935 & $1.608-2.328$ & \\
\hline $\mathrm{N} 3 \mathrm{a}$ & 2.821 & $2.327-3.420$ & & 2.807 & $2.316-3.404$ & \\
\hline $\mathrm{N} 3 \mathrm{~b}$ & 5.208 & $4.017-6.750$ & & 5.282 & $4.086-6.829$ & \\
\hline Lymphovascular invasion & & & 0.004 & & & 0.002 \\
\hline \multicolumn{7}{|l|}{ No } \\
\hline Yes & 1.230 & $1.067-1.418$ & & 1.245 & $1.080-1.434$ & \\
\hline Borrmann type & & & 0.006 & & & \\
\hline \multicolumn{7}{|l|}{ Other types } \\
\hline Type IV & 1.384 & $1.097-1.745$ & & & & \\
\hline Novel pT classification & & & & & & 0.000 \\
\hline \multicolumn{7}{|l|}{$\mathrm{T} 2$} \\
\hline $\mathrm{T} 3$ & & & & 1.370 & $1.132-1.658$ & \\
\hline $\mathrm{T} 4 \mathrm{a}$ & & & & 1.573 & $1.276-1.939$ & \\
\hline $\mathrm{T} 4 \mathrm{~b}$ & & & & 2.312 & $1.828-2.924$ & \\
\hline
\end{tabular}

Abbreviations: HR, hazard ratio; CI, confidence interval; UICC/AJCC, International Union Against Cancer/American Joint Committee on Cancer.

a, Step 1, with consideration of all significantly important prognostic factors in univariate analysis, except for the novel $\mathrm{pT}$ classification

b, Step 2, with consideration of all significantly important prognostic factors in univariate analysis, including the novel pT classification 
Figure 1

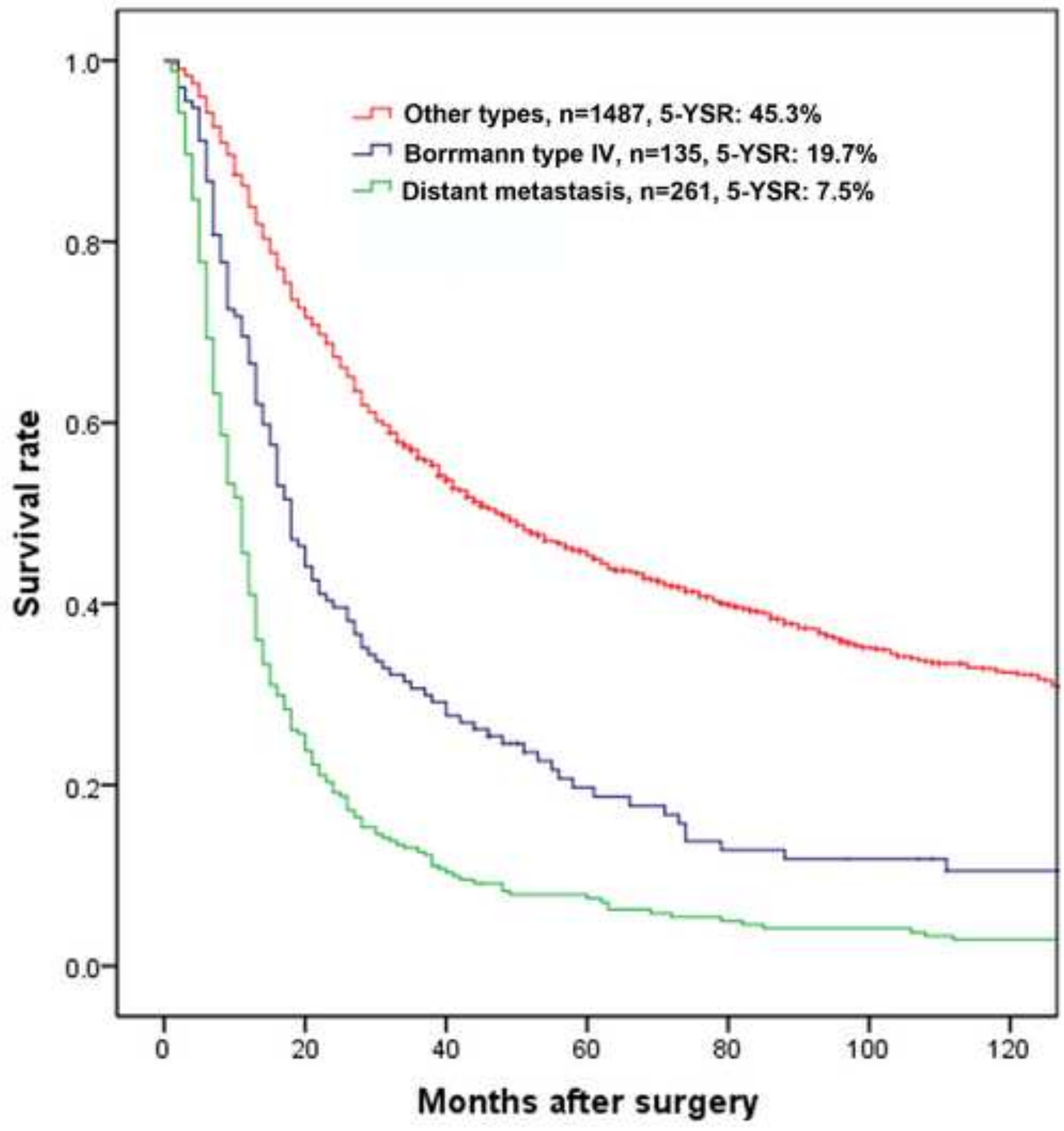



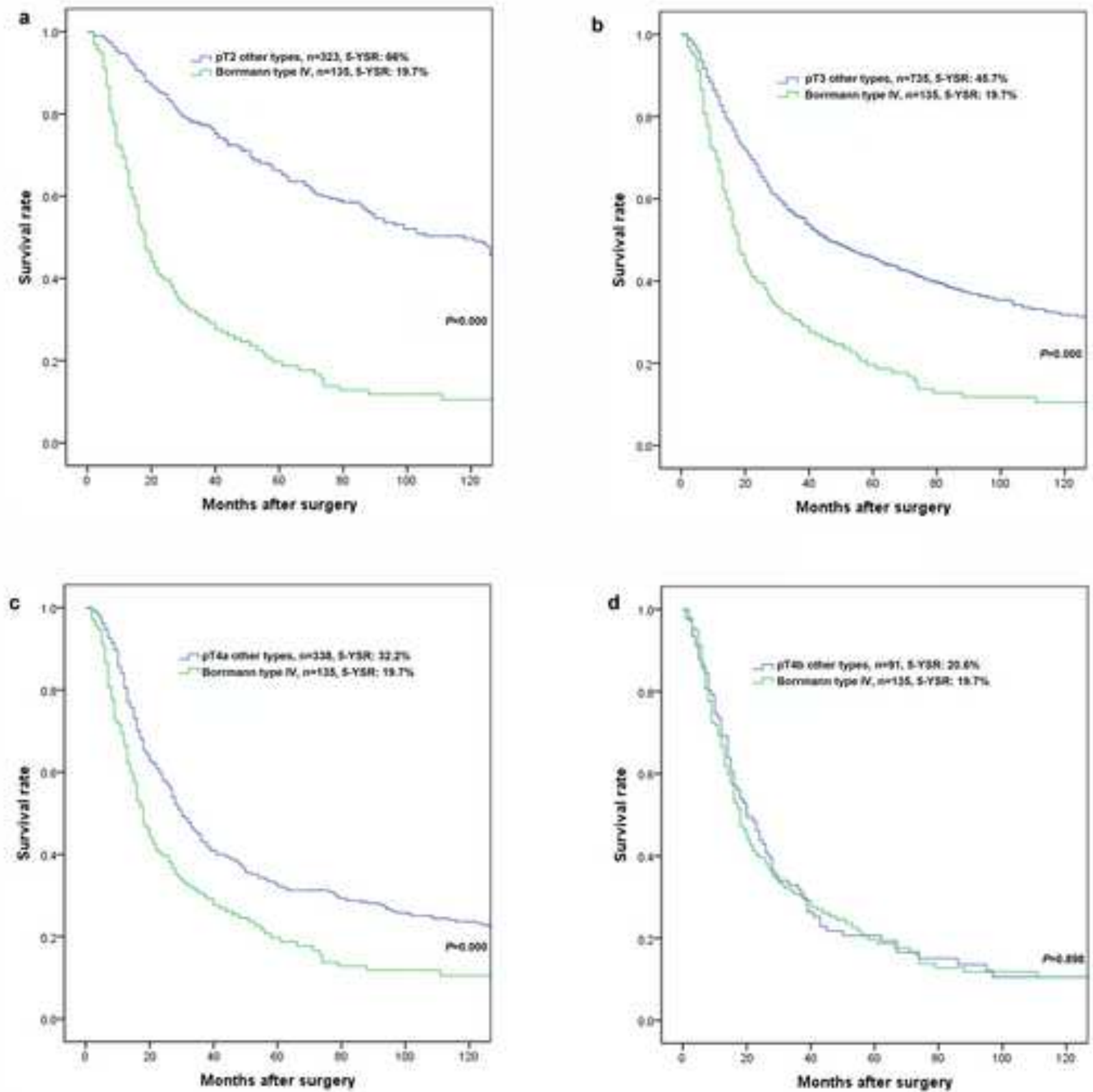

Figure 2 
Figure 4
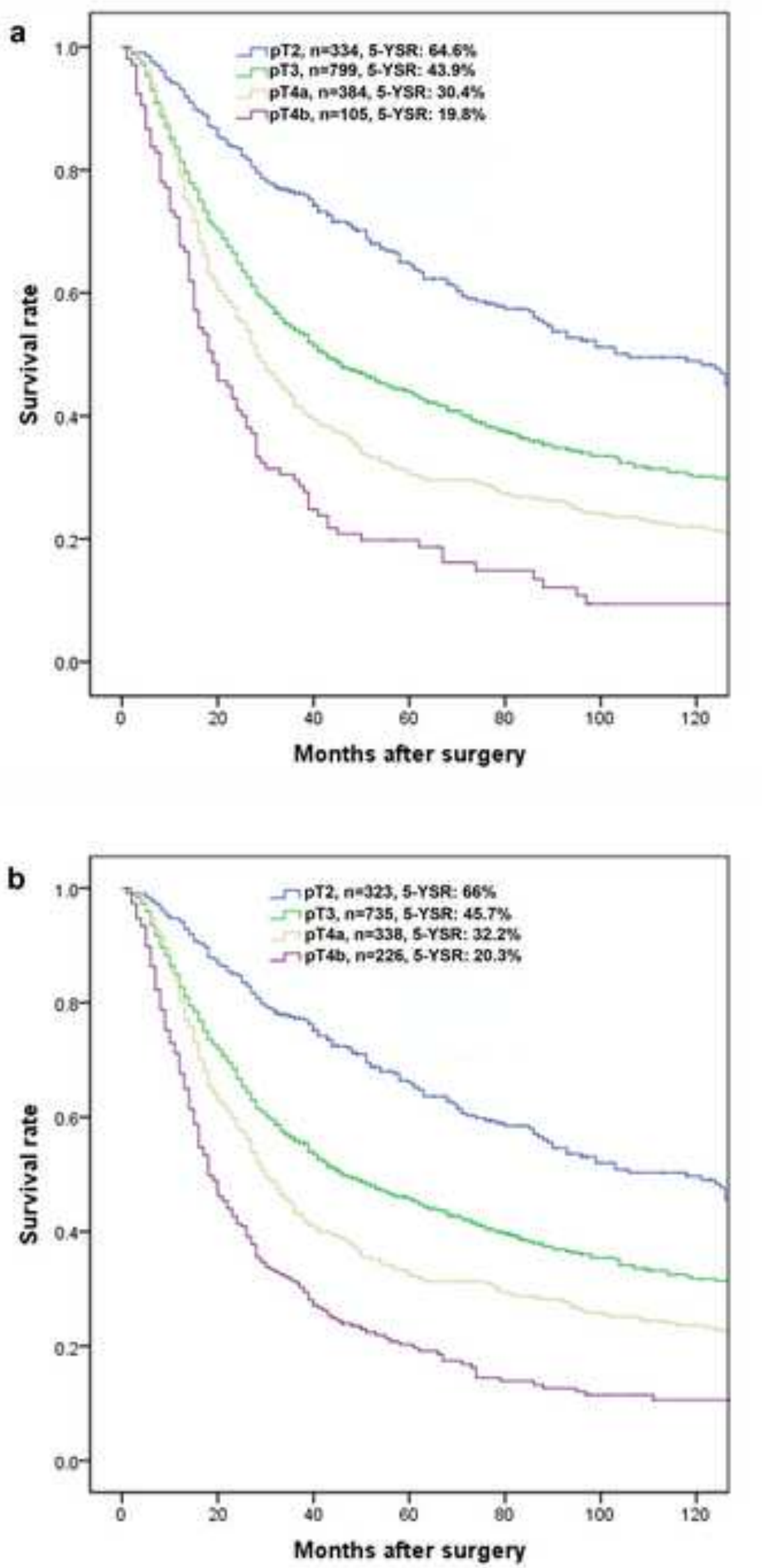

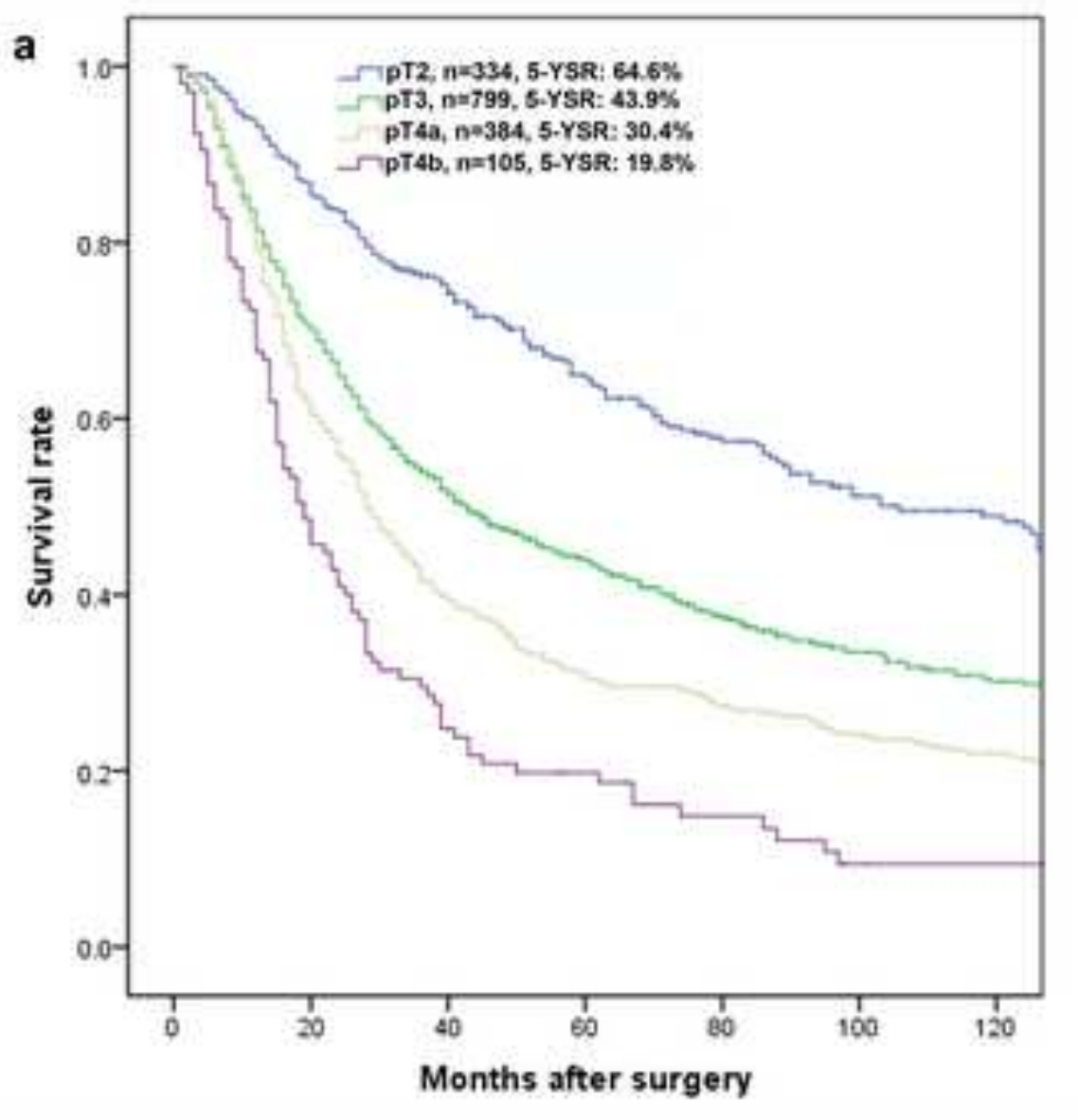

Months after surgery

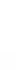

